\title{
A conceptual framework for the management of knowledge in a knowledge-based enterprise
}

\author{
Daniel F. Botha \\ Graduate School of Business, University of Stellenbosch, P.O. Box 610, Bellville, 7535 South Africa
}

Received July 20000

\begin{abstract}
Knowledge is at present recognised as a company`s most valuable asset and strategic resource in the creation of a competitive advantage. The ability and capacity to manage this recently accentuated intangible asset is fast becoming the most emphasised and critical executive skill for the management of a knowledge-based enterprise. The action-oriented and changing characteristics of knowledge place it in the context of innovation, analysis, synthesis, creativity and value judgement. This study explores the possibility to describe a company knowledge profile that will sufficiently reflect the company's capacity and capability to act in the new knowledge economy. The application of the knowledge profile and certain specific knowledge processors to a knowledge processing activity to obtain a knowledge yield is examined. It is derived that the knowledge yield will not only comprise of new products and services but also of newly created knowledge. This assumption is tested against Nonaka et al. 's model for a knowledge-creating company. It is suggested that the newly created knowledge will, in turn, enhance the company's knowledge profile. The knowledge yield will subsequently reflect on the company's performance and market value. It is argued that certain elements, constructs and concepts on knowledge management could be presented as an integrative whole by a generic conceptual framework. Considerations to be taken into account when contemplating the implementation of knowledge management as a process is discussed.
\end{abstract}

\section{Introduction}

With the advent of the Information Age the construct of knowledge management came into being and has given rise to a proliferation of research and publications in the academic and business realms of management. Peter Drucker (Ruggles, 1998: 80), wrote that 'knowledge has become the key economic resource and the dominant - and perhaps even the only source of comparative advantage'. In this statement two concepts - knowledge as an economic resource and knowledge as a source of competitive advantage - made significant impact on the traditional management approach and demanded a paradigm shift. This in turn created an abundance of new constructs and concepts - like intellectual capital, human capital, structural capital, knowledge capital, customer capital, human intellectual assets, intangible assets, knowledge worker, competent employee - all emphasising the utilisation of a scarce and special kind of human resource.

The consequent implications for the way a business is run are far-reaching and dramatic, influencing everything from a company's strategy to its products, from its processes to its organisational structures. Knowledge is now universally recognised as the organisation's most valuable asset and strategic resource. In the language of the accountant it is aptly termed the intellectual capital of the knowledge-based enterprise (Edvinsson \& Malone, 1997). The ability and capacity to manage this newly found human intellectual capital, and to convert it into useful market offerings - products and services - is fast becoming the most emphasised and critical executive skill for the management of enterprises in the Post-Industrial Era.

Knowledge, the knowledge worker and the knowledge-based enterprise - some terminology

In the perused literature no consensus or universal acceptance on a singular definition of knowledge could be found. It seems that a clear definition of knowledge has proven to be elusive over the years. Many authors confuse the concepts of knowledge and information and many a time the term knowledge is simply used in place of information (Nonaka \& Takeuchi, 1995: 58). A great trap in knowledge management is using information management tools and concepts to design knowledge management systems (McDermott, 1999: 104). Albert Einstein is quoted to have said that, 'knowledge is experience, everything else is just information'. Nonaka et al. (1995: 57-58) make three observations to describe how knowledge is similar to and different from information. First, knowledge unlike information is about beliefs and commitment. Knowledge is a function of a particular stance, perspective, or intention. Second, knowledge, unlike information, is about action. It is always knowledge 'to some end'. And third, knowledge, like information, is about meaning. It is context-specific and relational.

Sveiby (1997: 29-35) describes knowledge as tacit, as action-oriented, as based on rules, as individual and as constantly changing. Nonaka et al. (1995: 58) go further and consider knowledge as a dynamic human process of justifying personal belief towards the 'truth'. They state (1995: 56) that the comerstone of their 'epistemology' (theory of organisational knowledge creation) is the distinction between tacit and explicit knowledge. This they consider as one dimension of knowledge creation, whilst the second dimension is their own distinctive 'ontology', which is concerned with levels of knowledge creating entities (individual, group, organisational and inter-organisational). The distinction they make between tacit knowledge and explicit knowledge (1995: 59) is that tacit knowledge is personal, context-specific, and therefore hard to formalise and communicate. Explicit or 'codified' knowledge, on the other hand, refers to knowledge that is transmittable in formal, systematic language. They furthermore segmented tacit knowledge into two dimensions; namely, the technical dimension and the cognitive dimension (1995: 8). 
They anchor their dynamic model of knowledge creation on the critical assumption that human knowledge is created and expanded through social interaction between tacit and explicit knowledge and call the process 'knowledge conversion' (1995: 61).

For the purpose of this article the action-oriented and constantly changing characteristics of knowledge are favoured and the interaction between tacit and explicit knowledge is recognised. This approach places knowledge in the context of innovation, analysis, synthesis, creativity and value judgement.

With this descriptive expression of knowledge as basis, the definition of a knowledge worker can now be attempted. Firstly, knowledge workers can be regarded as highly qualified and highly educated professionals. Secondly, they add value through their ideas, their analysis, their judgement, their syntheses, and their designs (Horibe, 1999: xi). Thirdly, their work consists largely of converting information into knowledge by mostly using their own competencies and sometimes the assistance of suppliers of information or specialised knowledge.

The knowledge-based enterprise is a leaming organisation that recognises knowledge as a strategic resource and creates knowledge that can be processed into useful external offerings by exploiting the knowledge power of its intellectual capital of which the knowledge worker is a critical component. A learning organisation is an organisation skilled at creating, acquiring, and transferring knowledge, and at modifying its behaviour to reflect new knowledge and insights (Garvin, 1993: 80).
For their theory of organisational knowledge creation Nonaka et al. (1995: 56-90) postulated four modes of knowledge conversion based on the assumption that knowledge is created through the interaction between tacit and explicit knowl. edge. The four modes, socialisation, externalisation, combination and internalisation were contextualized in their epistemological and ontological dimensions to demonstrate a spiral process of organisational knowledge creation. Coupled with certain enabling conditions and incorporating the time dimension in their theory they presented a five-phase Model of the Organisational Knowledge Creation Process (1995: 83-89). Their model forms the basis of what they called the knowledge-creating company and supports the notion of a knowledge-based enterprise.

\section{Conceptual framework}

Valuable contributions on various aspects of knowledge and knowledge management was made by renown authors such as Nonaka et al. (1995), Probst, Raub \& Romhardt (1999) and Zack (1999) to present the results of their research, studies and perspectives in the format of models. The model presented by this article is yet another suggestion on the rationalisation of knowledge management concepts and constructs into a schematic whole. By identifying, accessing, analysing and critically assessing the information available in the extant literature on knowledge management and adding some personal tacit knowledge, an attempt was made to construct a conceptual framework that gives an integrative overview of the core elements of knowledge management. The model as depicted in Figure 1 is a schematic presentation of this

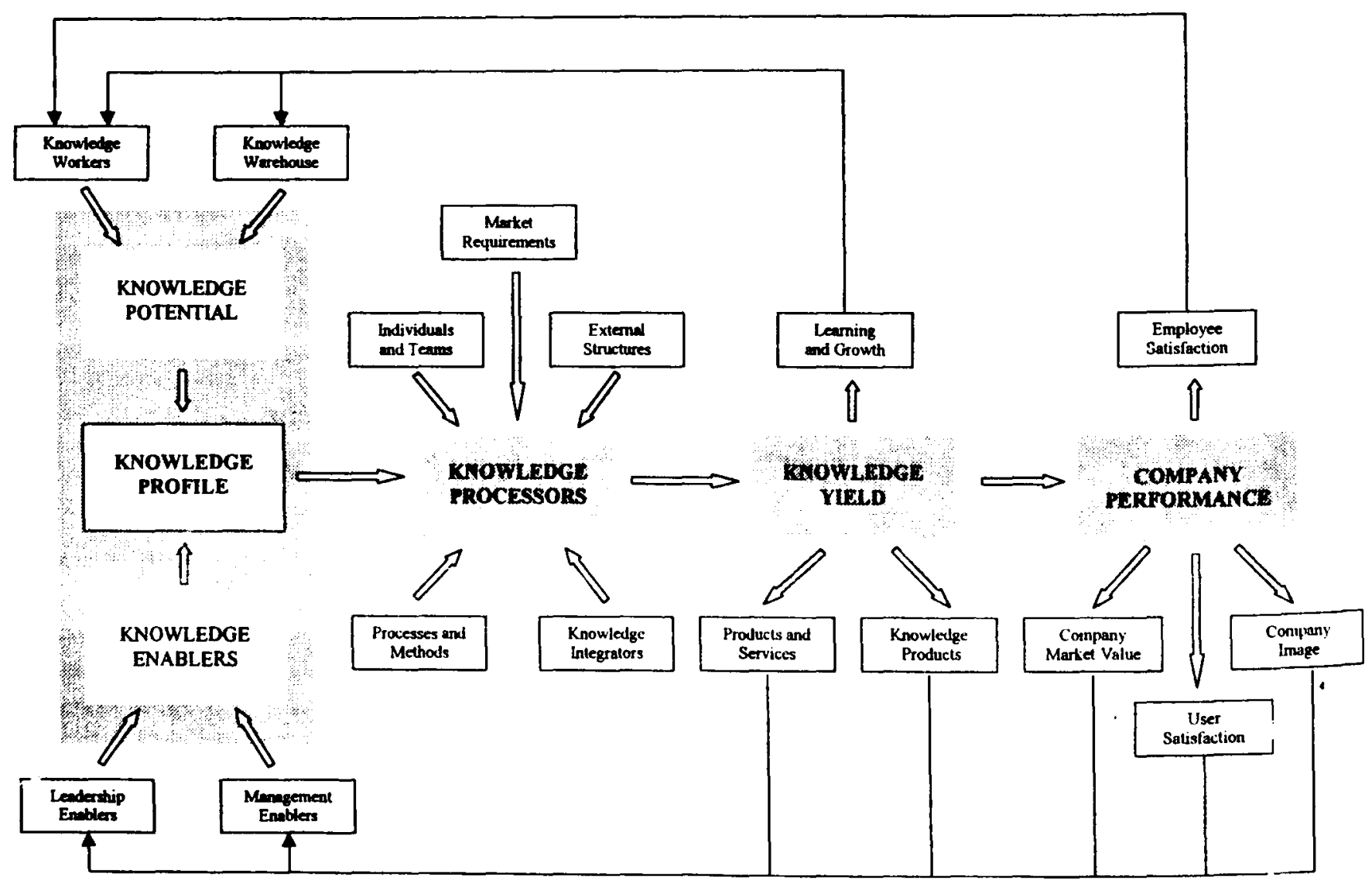

Figure 1 A conceptual framework for knowledge management 
conceptual framework and, at this stage, not validated by scientific empirical research.

The purpose of the article is to describe the various elements of the model and attempt to justify the knowledge management constructs and their integrative relationships. Argumentation will be based on the findings derived from the research of a recent literature study.

\section{Company knowledge profile}

Sveiby (1997: 37) defines knowledge as a capacity to act and states that one's capacity to act is created continuously by a process-of-knowing. A capacity to act lies in people - the competent people that work for the company - people in whom knowledge is embedded, and therefore aptly called the knowledge workers.

Furthermore, knowledge workers are also considered to be a critical part of the intellectual capital (Edvinsson et al., 1997), an intangible asset of the knowledge-based enterprise, and as for tangible assets, could be deployed to generate wealth.

A second source of capacitive knowledge is that which is represented in the company's formal and informal documentation. History files, minutes of project review meetings, design decision notes, engineering notes, designs, intellectual property rights, including patents and copyrights, as well as models, formulas, knowledge bases and concepts are examples of this source of knowledge - a source that is often grossly neglected in many companies. The tendency to reinvent the wheel is still strong, as many companies tend to ignore this resource when embarking on new ventures.

If, however, this knowledge is systematically and consciously collected, evaluated, stored and made accessible as information, it could become an invaluable intangible asset in the company's knowledge capacity. The collective noun, popularised by the literature, for this source of knowledge is the knowledge warehouse.

From the discussion above it is clear that both the knowledge worker and the knowledge warehouse gives the company a capacity to act (see Figure 2) and can therefore be collectively called the knowledge potential of the company.

With the capacity to act - the knowledge potential - established, causality dictates that the ability to act should follow.

As early as 1968 Porter \& Lawler (Myers, 1996: 181) identified the enabling organisation in their empirical research as an important element for successfully motivating personnel to achieve superior performance. This coupled with role and

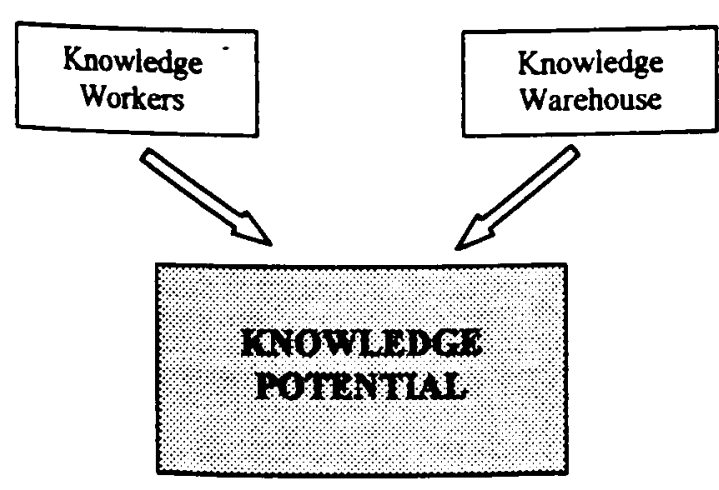

Figure 2 Capacity to act goal clarity was the company's contribution, whilst the employee supplied his/her task and domain relevant skills and personal effectiveness.

Roth \& Marucheck (1994: 2) in their research paper on the knowledge factory paradigm called processes, empowered workers, teams, seamless infrastructure and boundaryless organisations the 'enablers' of the knowledge factory. An enabling organisation is considered to be an organisation that has created the capability to utilise its assets towards the creation of wealth for its stakeholders. For the knowledge-based enterprise that has the capacity to act, to be an enabling organisation, the capability to act, must therefore be created. The organisational structures, systems and processes, deployed in an organisational climate and culture that supports and promotes knowledge deployment can therefore be called the knowledge enablers. These enablers will give the enterprise the means to act on, and apply, the knowledge potential.

However, the knowledge potential need to be focussed to produce specific market offerings and to achieve specified results, thus direction will have to be provided as well. Strategic plans, objectives and goals set within the company's vision, mission and value statements and communicated to lower levels will provide this direction. Horibe stated:

'The logic for creating mission and values statements that people believe in still holds true. If people believe in what the company's doing, they're more likely to contribute their intellectual capital to it' (1999: 253). These collective directional functions will enable the knowledge role-players to apply the potential knowledge in a constructive and structured environment.

From the literature sufficient evidence exist to regard knowledge as a strategic resource and asset, which warrants the same, if not greater, top managerial attention than the traditional assets of the company usually receive. Therefore knowledge and knowledge management in a knowledgebased enterprise should be given prime priority when strategy and strategic plans are formulated. Nonaka et al. (1995: 74) refer to strategy as organisational intention and prescribe it as an enabling condition for organisational knowledge creation. They state that the essence of a knowledge strategy lies in developing the organisational capability to acquire, create, accumulate and exploit knowledge. The most critical element of corporate strategy is to conceptualise a vision about what kind of knowledge should be developed and to operationalize it into a management system for implementation.

Kotter (1990) in his book $A$ force for change argued that there is a difference between organisational leadership and organisational management, each fulfilling a different but equally important task. His arguments are directly applicable to the management of knowledge where the equally important functions of giving direction and supplying the means to the knowledge potential are critical to the enterprise's creation of wealth for its stakeholders. It can, therefore, be argued that the company's knowledge enablers can likewise be divided into leadership enablers and management enablers which collectively gives the company the capability to act (see Figure 3).

The enabling conditions, for a knowledge-creating company, described by Nonaka et al. (1995: 73-83), as intention, autonomy, fluctuation and creative chaos, redundancy and 


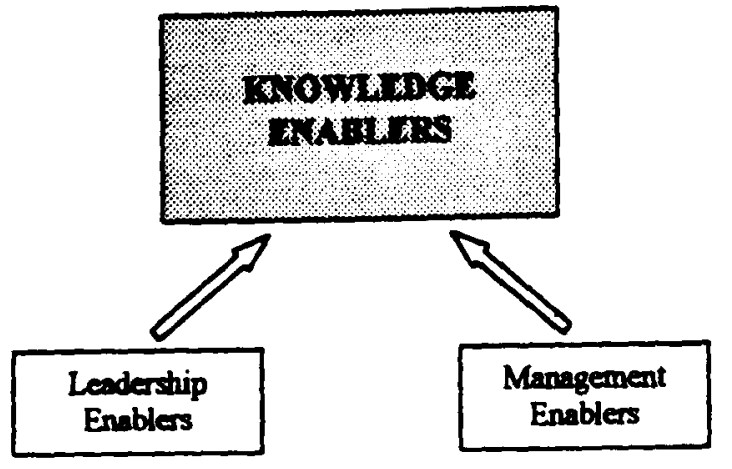

Figure 3 Capability to act

requisite variety should be fostered by the leadership and management enablers.

The Oxford dictionary defines a profile amongst others as: a graph, table etc. representing the extent to which a person, field or object exhibits various tested characteristics. In the same dictionary a characteristic is defined as: $a$ distinguishing quality, attribute, or trait.

Based on these definitions it is postulated that the distinguishing qualities, attributes, and traits of a knowledge-based company be collectively called the company's knowledge profile and that these characteristics be sufficiently represented by the company's knowledge potential and knowledge enablers.

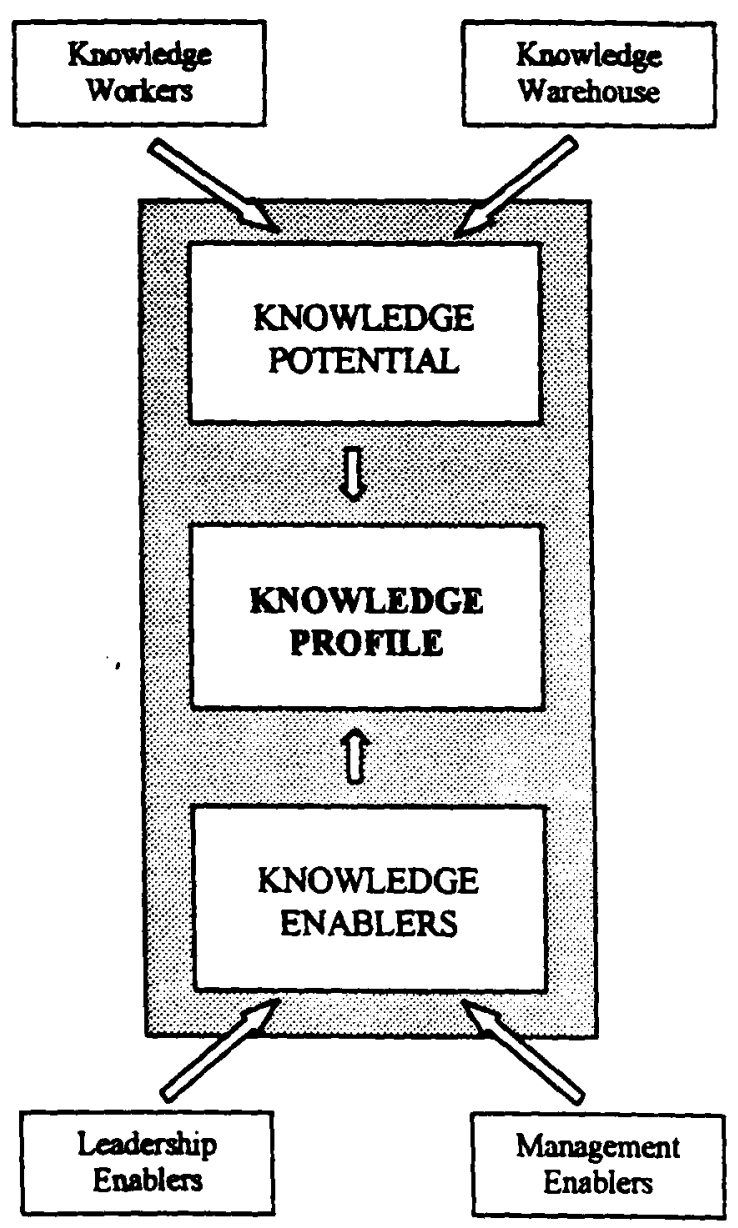

Figure 4 A company knowledge profile
It is therefore suggested that the descriptive elements of a company's capacity and capability to act reside in the knowledge profile of the company as illustrated in Figure 4.

\section{Knowledge processors}

If it is accepted that the knowledge profile of a company gives it the capacity and capability to act then causality dictates that action or activity should follow.

On knowledge in action, Davenport \& Prusak wrote:

'One of the reasons that we find knowledge valuable is that it is close - and closer than data or information to action. Knowledge can and should be evaluated by the decisions or actions to which it leads. Of course, since knowledge and decisions usually reside in people's heads, it can be difficult to trace the path between knowledge and action. Increasingly, knowledge and related intangibles not only make business go but are part or all of the "products" firms offer' (1998: 6).

In the literature much attention is given to knowledge acquisition, transfer, exchange and distribution but little on the actual activity of knowledge processing. All of these - acquisition, transfer, exchange and distribution - are functions which are supported by the knowledge warehouse and actually takes place before knowledge is processed into useful products and services. Widespread reference is made of tools, aids and integrators to manipulate, mobilise and engineer knowledge into required, specified and identified product and service offerings - all of which are usually technology-based systems. Little mention, however, is made of the collective capability to perform the integrated activity of knowledge processing. For the purpose of this article the elements of this collective capability will be called the knowledge processors. Nonaka et al. (1995: 61) describes knowledge conversion as the interaction between tacit and explicit knowledge in organisational knowledge creation and should not be confused with the author's view of the knowledge processing activity. The view is held that knowledge conversion and, therefore, company knowledge creation, take place during the knowledge processing activity, as suggested by this article.

Individuals and teams, activators, processes, integrators and external structures are the elements that could be commonly identified to be deemed necessary for the activity of knowledge processing to take place (see Figure 4). All these elements must be managed, orchestrated and integrated to create the required outputs. The first logical event will be to identify a need for the utilisation and application of the company's knowledge profile, that is to identify the activators.

Activators of the knowledge processing activity could initiate from different sources, both internal and external to the company. Most authors on core competencies and competitive advantage agree that sustained internal generation, initiation, and innovation of market offerings by pro-active companies give them a distinctive edge over the traditional re-active approach of industrial era companies. Prahalad \& Hamel fittingly commented that:

'The critical task for management is to create an organization capable of infusing products with irresistible functionality or, better yet, creating products that customers need but have not yet even imagined' (1990: 80). 
Internal awareness on inventing new markets, quickly entering emerging markets and dramatically shifting patterns of customer choice in established markets, should be fostered in company culture. These should be the prime activators for knowledge processing activities.

External activators, like tendering and quoting for the delivery of goods and services, bidding for contracts, re-acting to client problems and needs and responding to invitations to submit proposals for projects are likewise important opportunities to utilise the company's knowledge profile.

To make the knowledge processing activity dynamic, people - with knowledge - are of course a necessity and certainly the most important element of value addition in the process. They, the knowledge workers, add value through their ideas, their innovativeness, their analysis, their judgement, their syntheses and their designs. They should know why their knowledge is needed and how, when and where to apply it. Knowledge workers with specialised knowledge and skills can be assigned to individual tasks to produce specified outcomes, but in truly knowledge-based organisations they are usually assigned to teams that are specifically composed to tackle allocated assignments. The forming of teams with members representing internal and external structures (Nonaka's ontological dimension), will promote tacit and explicit knowledge interaction (Nonaka's epistemological dimension), and lead to the creation of new knowledge if supported by the inputs from the company's knowledge profile (Nonaka's enabling conditions).

The processing activity must be conducted in a rational and structured way therefore careful orchestration is needed. This orchestration is again directional (how) and resource (with what) dependent.

How the conversion activity will be conducted is dependent on the processes and methods employed by the team tasked to do the job. The processes could be standard company procedures and methods, it could be processes derived from professional codes of conduct and standards, or it could be processes tailored to the specific needs of the task and designed by the task-group. Process knowledge could also be a company specific core competence that will be a significant contributor to competitive advantage.

Influential process movement literature defines process as $a$ collection of activities that take one or more inputs and create an output that is of value to the end user (Keen, 1997: 17). Processes that are of importance to knowledge conversion are core, enterprise level processes, that is, natural, beginning-toend processes such as order processing, new product development, system and concurrent engineering, integrated logistic support, supply chain management (SCM), or integrated design and manufacturing. Often knowledge conversion could lead to process re-orientation/re-engineering whereby processes become major axes around which organisation is structured and managed. Keen (1997: 16) soundly argues that firms should only invest in processes that make a difference. He singles out salient processes as the processes that relate most directly to the firm's identity - those that visibly differentiate it from its competitors - and the priority activities that keep the engine of every-day competitive performance running. It is therefore recognised that these processes are like- wise the significant processes in the knowledge processing activity under discussion.

Business process re-engineering (BPR), total quality management (TQM), time-based competition, the team-based organisation, and other strategies for business success are all part of the Process Movement (Keen, 1997: 1). It is not suggested that the knowledge processing activity, described here, should be placed in the same category. The knowledge processing activity has an operational focus instead of a strategic focus.

One the most popular and widely used processes in the creation of new products and services, that warrants mention at this stage, is the Project Management Process (PMS) of which the Project Management Body of Knowledge (PM$\mathrm{BOK}$ ) is widely accepted as a standard by the project management community. In this process knowledge management is also of critical importance.

The next important input to the knowledge processing activity, identified in the literature, could be called the knowledge integrators. For the purposes of this article knowledge integrators are defined as all those computer-based communication and information technology systems and aids that could be directly employed in the knowledge processing activity. From the literature two broad categories of knowledge integrators could be identified.

The first is categorised as Knowledge-Based Systems (KBS). In the publication Knowledge management and its integrative elements, edited by Liebowitz \& Wilcox (1997), these systems are comprehensively discussed as aids in the processing of knowledge. In one of the papers Cochran, Vedhanayagam \& Blagg (Liebowitz, 1997: 91) define KBS as computer information systems that explicitly represent and process knowledge. They specifically link Artificial Intelligence $(\mathrm{Al})$ techniques to the embedding of vast task-specific knowledge of experts in an electronic knowledge base. This knowledge could be in the form of facts, rules or procedures, heuristics, strategies, and causal domain theories. Other authors like Davenport \& Prusak (1998: 125-140) also add Expert Systems (ES), Neural Networks (NN), Case-based Reasoning (CBR) and Decision Support Systems (DSS) to their list of knowledge management tools.

The second category of knowledge integrators is identified as Communication and Information Technology Systems. These systems encompass all computer-based systems and aids that could be used by the main role-players during the knowledge processing activity. Typical technologies in this category will be tools like GroupWare, video-conferencing, inter-, extra-, and intranets, e-mail and CAE, CAD and CAM. Davenport \& Prusak (1998: 128) refer to these integrators as infrastructural technologies that should not be overlooked by managers when facilitating knowledge processing

It should, however, be kept in mind that knowledge technologies are solely aids in the knowledge processing activity, since it is the value added by people - context, experience. judgement, and interpretation - that transforms data and information into knowledge. It is the ability to capture and manage those human additions that make information technologies particularly suited to dealing with knowledge. Knowledge technologies are more likely to be employed in an interactive and iterative manner by their users. Therefore, the 
roles of people in knowledge technologies are integral to their success. The role of middle management in the new flat organisational structures of knowledge-based companies is regularly debated in the literature. Some authors make out a strong case that we may soon experience the extinction of this species. Nonaka (1998: 45), on the other hand, argues that middle management should be reassigned to act as knowledge integrators or as knowledge engineers and that they have a significant role to play in this regard. If the importance and extent of the knowledge processing activity, as described by this article, is taken into account, this viewpoint is fully supported.

The final important input to the knowledge processing activity could be called the external structures. Sveiby (1997) identified external structures, which includes relationships with customers and suppliers, as one of the three main intangible assets of a knowledge-based company. The other two are employee competence - discussed under knowledge workers - and internal structures - included in management enablers. He argues that the most valuable revenue from customers is not money but knowledge and advises managers that it is important to select customers with intangible revenues in mind. The use of client projects to develop new products, processes, and methods and for on-the-job training and development are but some examples of knowledge revenues and knowledge growth obtainable from clients.

Another valuable source of knowledge from external structures is alliances. Badaracco (1991) undertook a four-year study on the business impact of strategic alliances in big corporations. He argues that the reason why corporations like General Motors and IBM took down their corporate walls and exposed their own organisational practices and strategies to their competitors was to capitalise on knowledge. Formidable time and start-up costs needed to develop new products and enter new markets are forcing companies to enter into strategic alliances. Roth et al. (1994: 19) stresses the use of boundary spanning relationships by world class manufacturers to differentiate themselves. They furthermore revealed data that world class groups are more apt than their non-world class counterparts to integrate with suppliers, customers and strategic partners through strategic alliances, joint ventures and supplier certification. Sufficient evidence exist to add competitors and other enterprises in the knowledge-based industry, as knowledge input sources, to the list of external structures.

After the recent (February 2000) chaos created by unknown hackers to the Internet services supplied by Yahoo, CNN, Time-Warner and others, President Bill Clinton was approached by the industry on possible stricter legislation. His reply, apart from promising a review of present legislation, was that the Internet society should work together and share their knowledge to prevent a similar happening in the future. Sharing knowledge on Internet security measures and technology does not necessarily affect the core competencies and competitiveness of the respective Internet companies, but could be mutually beneficial to the service they collectively provide.

It is, therefore, deduced that knowledge and information gleaned from customers, suppliers and competitors can be of crucial significance to the knowledge processing activity.

\section{Knowledge yield}

The knowledge yield is of course the main fruits of labour of the knowledge processing activity and the primary objective of the whole knowledge management exercise thus far (see Figure 5). In a knowledge-based enterprise the output from the knowledge yield should not be regarded as a single standalone product or service but as a complex product/service 'bundle' which are called offerings by Roth et al. (1994: 8), Offerings combine the value of the physical product with intangibles such as customisation, perceived quality, speed of delivery, support services, and value for money.

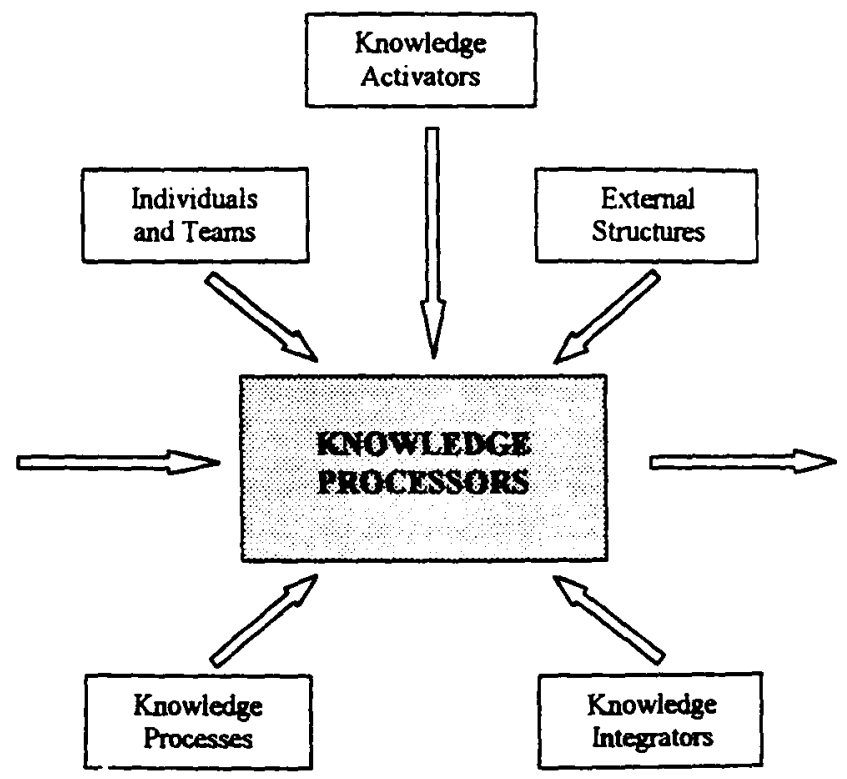

Figure 5 Results of the processing activity

Knowledge in itself could also be regarded as a primary output from the knowledge yield. This could be in two different formats - externally and internally. External knowledge yield is seen as a final product if it is immediately used by a customer or consumed in the transformation, such as in the case of consulting, technical and support services, and knowledge work like ad hoc analysis, feasibility studies, diagnostic tasks and problem solving.

Most companies do not always realise the importance of the management of the internal knowledge creation and yield. Knowledge-based enterprises should not only be concemed with leveraging knowledge for immediate consumption, but also with accumulating relevant knowledge for future use Learning itself must be regarded as an output of the knowledge processing activity in a knowledge-based enterprise

The value of knowledge as an asset could be enhanced if the company - employees and management - makes a conscious and planned effort to capture and document the behaviour of processes. By using intelligent technology or any other suitable means, better solutions for the next round of knowledge processing could be generated (Roth et al., 1994: 9). Not only is the capturing and documentation of prime importance, but also, of equal importance will be the feedback and distribution of such knowledge to the rest of the knowledge workers and the knowledge warehouse as illustrated in Figure 1 . 


\section{Company performance}

The final measure of successful knowledge yield will be found in the company performance parameters as illustrated in Figure 6. Apart from user satisfaction with company offerings the other knowledge bearing outputs such as company market value, company image, and employee satisfaction all contain elements of which the metrics are crucial to the evaluation of the knowledge yield and the preceding knowledge processing activity.

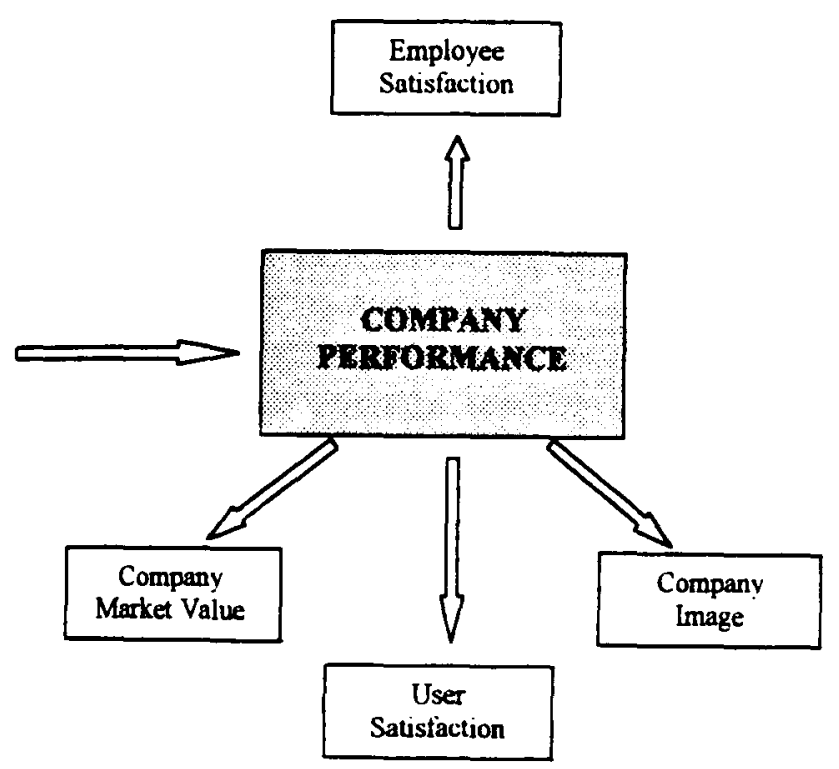

Figure 6 Results of the company offerings

In Managing knowledge Albert \& Bradley (1997: 64-81), after an extensive literature study, find that pecuniary measures alone are no longer sufficient to describe company performance. They then quote Eccles (Albert et al., 1997: 73) who prescribes 'a new philosophy of performance measurement, where financial figures are not the only basis for decision-making by managers and external investors'. Eccles proposes that financial figures should be supplemented by measures of customer satisfaction, quality, market share and human resources.

Kaplan \& Norton (1996: 7-8) propose that company performance can be viewed from four different perspectives, namely, a financial perspective, an internal business perspective, a customer perspective, and a learning and growth perspective. From this they derived a performance model, called The Balanced Scorecard, in which they emphasised a strong relationship and interaction between financial management, customer satisfaction, employee satisfaction, and process improvement when company performance is evaluated. The author argues that user satisfaction, employee satisfaction, company market value and company image are sufficient parameters to determine the effective use of the knowledge profile and the knowledge processors in creating company performance.

What is important for the scope of this article, however, is the structured and sustained feedback of the company's performance on these parameters to the knowledge profile in order to contribute to the knowledge growth strategy and to update the knowledge warehouse.

\section{Considerations for implementation of knowledge management}

In the world of management theories and practices, the last couple of decades belonged to the process movement or the process brokers. Most of the influential business books and rallying cries of the 1990s have focussed on process improvement. Business process re-engineering, total quality management (TQM), time-based competition, the team-based organisation, system and concurrent engineering, integrated SCM and logistics, and other strategies for superior business performance are all part of the process movement (Keen, 1997: 1). Even in the realm of business technology systems, like SAP and Baan, the focus was on process improvement. Keen describes the success of the process movement as follows:

'Each process improvement strategy can lead to notable successes. Firms that undertook process reform have reported radical, not incremental, improvements. Dramatic time and cost savings, quality improvements, and staff productivity are commonplace' (1997: 1-2).

But then goes on and comments on the Process Paradox:

'Not all the news about process transformation has been good, however. Many firms have found that even dramatic levels of process improvement often don't translate into better business performance. In fact, they may not even prevent disaster, let alone bring success' (Keen, 1997: 2).

The reasons given for failures experienced by companies who followed the process movement are two fold. One is choosing the right processes for re-engineering (decision) and the second is the ability to implement (action). Not only should companies invest in the processes that make a difference - judged on the salience and worth of the process - but the company must also demonstrate the dynamic capability to implement the changes.

In a notable paper by Pfeffer \& Sutton (1999: 88-89) they make out a well-substantiated argument that the failure of new business ideas, theories and research findings to produce significant improvement in company performance is due to a lack of dynamic implementation action. They state that:

'This conclusion means that although knowledge creation, benchmarking, and knowledge management may be important, transforming knowledge into organizational action is at least as important to organizational success' (1999: 88-89).

Furthermore, some research demonstrated that the success of most interventions designed to improve organisational performance depends largely on implementing what is already known, rather than from adopting new or previously unknown ways of doing things.

Based on these debated points it is argued that the same care should be taken in the implementation of knowledge management. New process implementation, especially in large corporations could, at best, be rather traumatic and disruptive and not always cost effective. Rather than implementing a new knowledge management process, whereby new knowledge management structures are instituted and new knowledge management responsibilities are assigned, it is suggested that embedded company culture, processes, 
structures and tasks be analysed and systematically re-structured and changed to absorb knowledge management as a new way of life. The changes should be consistent with the Japanese concept of kaizen - continuous improvement - most changes being small, simple, and in many cases, quite commonsensical (Keen, 1999: 88). This will entail the identification of processes of salience and worth and the associated tasks needed to perform them.

\section{Conclusion}

Conclusive evidence from the literature was cited to emphatically state that the management of knowledge in a knowledge-based enterprise is essential for sustained competitive advantage and that knowledge should be viewed as an important intangible asset and wealth generator that warrants strategic attention.

Many companies in South Africa have unwittingly been active in certain aspects of knowledge management and have implicitly applied knowledge management principles. Very few, however, have instituted knowledge management as a formalised practice. The era of the explicit practising of knowledge management has arrived and companies that choose to ignore this will sacrifice competitive advantage and sustained growth. The model suggested in this article is an attempt to focus in a causal, structured and logic way, on the primary elements, that are significant in practising knowledge management in knowledge-based enterprises.

The construction of a company knowledge profile, in itself, could serve as a viable audit to evaluate the company's knowledge capacity and capability. Likewise, could a structured analysis and a critical stocktaking of the company's knowledge processors be a fair indicator of the company's preparedness to comply with the needs for effective and efficient knowledge creation and processing. The conceptual framework also attempts to demonstrate that company performance cannot be divorced from the company's knowledge profile and knowledge processing activities and that the relationship is interdependent and linked by causality.

The conceptual framework suggested in this article needs further scientific research to empirically validate it as a viable management model.

The article finally argues that caution should be exercised on the immediate implementation of knowledge management as a process and proposes that the model be used to analyse the company's current knowledge management status before deciding on an implementation strategy.

\section{References}

Albert. S. \& Bradley, K. 1997. Knowledge management - experts agencies and organizations. Cambridge: Cambridge University Press, 215p.

Badaracco, Jr. J.L. 1991. The knowledge link - how firms compete through strategic alliances. Boston, Massachusetts: Harvard Business School Press. 189p

Davenport, H.T. \& Prusak, L. 1998. Working knowledge - how organizations manage what they know. Boston, Massachusetts: Harvard Business School Press. 199p.

Edvinsson. L. \& Malone. M.S. 1997. Intellectual capital - realizing your company's true value by finding its hidden brainpower. New York: HarperCollins Publishers. Inc.. 225p.

Garvin. D.A. 1993. Building a learning organization, Harvard Business Review, 71(4): 78-91

Horibe, F. 1999. Managing knowledge workers. Toronto, Ontario: John Wiley \& Sons, 292p

Kaplan. R.S. \& Norton, D.P. 1996. The balanced scorecard. Boston. Massachusetts: Harvard Business School Press. 322p

Keen, P.G.W. 1997. The process edge - creating value where it counts. Boston, Massachusetts: Harvard Business School Press, $185 \mathrm{p}$.

Kotter. J.P. 1990. A force for change how leadership differs from management. New York: The Free Press, $\Lambda$ Division of Macmillan, Inc., 180p.

Liebowitz, J. \& Wilcox, L.C. 1997. Knowledge management and its integrative elements. Boca Raton, Florida: CRC Press. 199p.

McDermott, R. 1999. Why information technology inspired but cannot deliver knowledge management, California Management Review: 41(4): 103-117.

Nonaka. I. \& Takeuchi, H. 1995. The knowledge-creating company. New York: Oxford University Press. 284p.

Pfeffer, J. \& Sutton. R.I. 1999. Knowing 'what' to do is not enough: turning knowledge into action. California Management Review. 42(1): 83-105

Prahalad, C. K. \& Hamel, G. 1990. The core competence of the corporation. Harvard Business Review, 68(3): 79-91

Probst. G.. Raub, S. \& Romhardt. K. 1999. Managing knowledge building blocks for success. Toronto, Ontario: John Wiley \& Sons, $368 \mathrm{p}$

Roth, A.V. \& Marucheck. A.S. 1994. The knowledge factory - paradigm for accelerated learning. Chapel Hill, North Carolina: University of North Carolina, Kenan-Flagler Business School, 52p.

Ruggles, R. 1998. The state of the notion: knowledge management in practice, California Management Review, 40(3): 80-89.

Sveiby, K.E. 1997. The new organizational wealth-managing \& measuring knowledge-based assets. San Francisco: Berrett-Koehler Publishers, Inc., 202p.

Zack, M.H. 1999. Knowledge and strategy. Boston, Massachusetts Butterworth-Heinemann, 312p. 